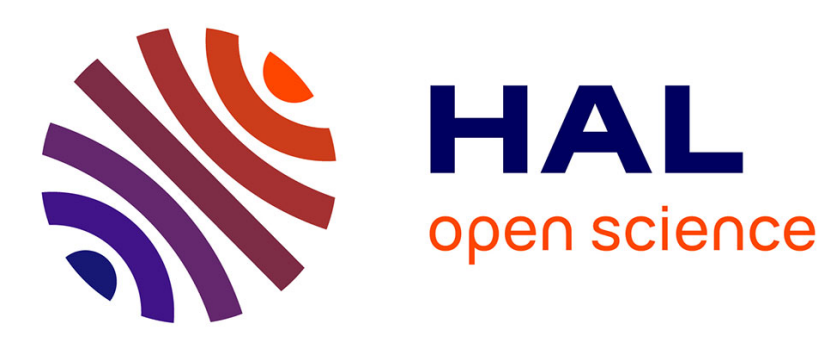

\title{
Nucleation-growth process of calcium carbonate on rotating disk electrode in mineral potable water
}

Zineb Belarbi, Jean Gamby, Laid Makhloufi, Bernard Tribollet

\section{To cite this version:}

Zineb Belarbi, Jean Gamby, Laid Makhloufi, Bernard Tribollet. Nucleation-growth process of calcium carbonate on rotating disk electrode in mineral potable water. Electrochimica Acta, 2013, 109, pp.623629. 10.1016/j.electacta.2013.07.148 . hal-00938092

\section{HAL Id: hal-00938092 \\ https://hal.sorbonne-universite.fr/hal-00938092}

Submitted on 9 Mar 2015

HAL is a multi-disciplinary open access archive for the deposit and dissemination of scientific research documents, whether they are published or not. The documents may come from teaching and research institutions in France or abroad, or from public or private research centers.
L'archive ouverte pluridisciplinaire HAL, est destinée au dépôt et à la diffusion de documents scientifiques de niveau recherche, publiés ou non, émanant des établissements d'enseignement et de recherche français ou étrangers, des laboratoires publics ou privés. 


\title{
Nucleation-growth process of calcium carbonate on rotating disk electrode in mineral potable water
}

\author{
Zineb Belarbi ${ }^{\text {a,b,c }}$, Jean Gamby ${ }^{\text {a, b, }{ }^{*}, 1}$, Laid Makhloufi ${ }^{\text {c }}$, Bernard Tribollet ${ }^{\text {a,b }}$ \\ ${ }^{a}$ CNRS, Laboratoire Interfaces et Systèmes Electrochimiques, UPR 15, F-75252 Paris, France \\ ${ }^{b}$ UPMC, LISE UPR 15 CNRS ; 4 Place Jussieu, case postale 133, F-75252 Paris, France \\ ${ }^{c}$ Laboratoire d'Electrochimie, Corrosion et de Valorisation Energétique (LECVE) \\ Faculté de Technologie, Université A. MIRA - Béjaia 06000, Algeria
}

\footnotetext{
* Corresponding author: jean.gamby@upmc.fr Tel: +33 1442736 40; Fax: +33 14427 4074;

${ }^{1}$ ISE member
} 


\begin{abstract}
This paper presents numerical simulation for interpretation of chronoamperometric experimental curves of nucleation-growth process of calcium carbonate on rotating disk carbon steel electrode. The simulation based on finite element resolution was carried out to solve the convective-diffusion equation in order to calcutate dioxygen gradient concentration at the electrode which allows the limiting current diffusion determination at various rotation speeds in the presence and absence of calcium carbonate. Methodology used in this paper opens a new way for chronoamperometric curve interpretation through analytical expression determination of lateral and vertical crystal growth rate on carbon steel, $k_{L}$ and $k_{V}$, respectively.
\end{abstract}

Keywords: Chronoamperometry; Calcium carbonate; Modeling; Nucleation-growth process; Simulation. 


\section{Introduction}

Calcium carbonate deposition leads to the formation of compact layers which show by themselves efficient protection properties with respect to dioxygen diffusion. Its precipitation remains a problem for industrial and domestic installations [1]. Several investigations were performed in order to get a better understanding about the $\mathrm{CaCO}_{3}$ crystallization process [24]. Gabrielli et al. $[5,6]$ have proposed a theoretical approach to interpret the measurement obtained at the first step of precipitation. It was demonstrated that whether the mass measurement was proportional to $t^{2}$, the nucleation was instantaneous whereas a $t^{3}$ proportionality corresponded to a progressive nucleation. Devos et al. [7, 8] have developed an original set-up for following calcite deposition by coupling electrogravimetry and optical measurements in an impinging jet cell. In this way, three kinds of information were accessible simultaneously: the mass of $\mathrm{CaCO}_{3}$ on the surface, the faradic current of dioxygen reduction, and the direct observation of the growth process under an optical microscope. It was clearly established that the growth rate of the vaterite was faster than the one measured for the calcite on the same electrode surface.

In order to quantify the scaling's power of water; electrochemical technique such as chronoamperometry (CA) was used for monitoring kinetic rate of $\mathrm{CaCO}_{3}$ precipitation on materials [9-11]. In brief, a metallic electrode was polarized at cathodic potential (-1 V vs $\mathrm{SCE}$ ) to promote the $\mathrm{O}_{2}$ reduction according to the equation 1

$$
\mathrm{O}_{2}+2 \mathrm{H}_{2} \mathrm{O}+4 e^{-} \rightarrow 4 \mathrm{OH}^{-}
$$

The formation of hydroxide ions at the electrode, from $\mathrm{O}_{2}$ reduction as displayed in equation 1 , increases the local $\mathrm{pH}[5]$ and makes easier the calcium carbonate precipitation into a solid crystalline phase according to the following chemicals reactions

$$
\mathrm{HCO}_{3}^{-}+\mathrm{OH}^{-} \Leftrightarrow \mathrm{CO}_{3}^{2-}+\mathrm{H}_{2} \mathrm{O} \text { (in bulk) }
$$




$$
\mathrm{Ca}^{2+}+\mathrm{CO}_{3}^{2-} \Leftrightarrow \mathrm{CaCO}_{3} \text { (at the interface) }
$$

The data analysis of the chronoamperometric curve is commonly used for investigating nucleation and growth kinetics of $\mathrm{CaCO}_{3}$ on metallic electrodes $[12,13]$. Until now, CA was used to classical determination of scaling time of calcite precipitation that is easy to use as a test. Indeed, the CA has permitted obtention of only partial information on the screening effect of the insulating scale deposit on the electrode surface and in particular, it has not allowed differentiation between $2-D$ and $3-D$ blocking. To a better data exploitation and understanding of nucleation-growth process, it appeared interesting to investigate experimentally and theoretically kinetics and mass transfer phenomena at mineral potable water solution/ carbon steel interface.

\section{Experimental}

\subsection{Electrochemical measurements}

Experiments were performed in mineral potable water containing the main species displayed in table 1 . The electrochemical measurement was conducted in a three electrode cell configuration. The working electrode was a carbon steel disk mounted on rotating disk electrode. Its surface was prepared by mechanical polishing with silicon carbide paper (grade 4000), rinsed thoroughly with bidistilled water before introduction in the cell. The area in contact with the mineral potable water was equal to $0.196 \mathrm{~cm}^{2}$. A platinum grid was used as a counter electrode. The potential was measured versus a saturated calomel electrode (SCE). Electrochemical experiments were driven under potentiostatic conditions using Biologic ${ }^{\circledR}$ interface. For all studies, the temperature of the cell was set at $20^{\circ} \mathrm{C}$. The current/ potential curves (I/E curves) were plotted at a scan rate of $1 \mathrm{mVs}^{-1}$ by a forward scan from an anodic potential $(-0.39 \mathrm{~V}$ vs SCE) to a cathodic potential (-1.9 V vs SCE) at various rotation speeds (100-1000 rpm). In order to generate the $\mathrm{CaCO}_{3}$ deposition, cathodic potential was applied at $-1 \mathrm{~V}$ vs SCE for a period of $140 \mathrm{~min}$ at $500 \mathrm{rpm}$. Electrochemical impedance spectroscopy 
(EIS) measurements were performed in situ as calcareous deposits were forming on electrodes polarized at $-1 \mathrm{~V}$ vs SCE with a rotation speed of $500 \mathrm{rpm}$. The impedances were measured in a relatively high frequency (HF) domain in order to reduce the EIS measurement time (25 $\mathrm{kHz}-0.1 \mathrm{~Hz})$

\subsection{Characterizations}

Ex situ characterization of the deposit obtained after 140 minutes of deposition was performed by SEM and X-ray diffraction (XRD). SEM pictures were obtained on a FEGSEM Zeiss Ultra55 microscope operated at $10 \mathrm{kV}$. The crystal structures of the calcareous deposits were investigated by X-ray diffraction (XRD) on a Diffractometer Panalytical with Prefix configuration using the $\mathrm{Cu}-\mathrm{K}_{\alpha}$ radiation $(1.54 \AA$ ). XRD analysis was carried out at room temperature $\left(20^{\circ} \mathrm{C}\right)$.

\subsection{Numerical simulation}

The mass transfer equations are solved using COMSOL Multiphysics 3.5, a commercial Finite Element Method (FEM) based software package. The computations were performed on a Windows7- 64 bits with Pentium (R) Dual-Cor CPU 2.30 GHz with 4 GB memory.

\section{Results and discussion}

\subsection{Formation of calcareous deposits on steel}

The voltammetry curves displayed in Fig. 1 were obtained just after immersion at various rotation speeds $(100-1000 \mathrm{rpm})$ at fixed scan rate of $1 \mathrm{mV} . \mathrm{s}^{-1}$ and for a potential window from -0.4 to $-1.9 \mathrm{~V}$ vs SCE in mineral potable water. The modulus of the cathodic current increases for each curve until reaching a plateau. This latter corresponds to the current limit of dioxygen reduction (see equation 1). Then, it follows a quick increase for more negative potential corresponding to water reduction into dihydrogen. In Fig. 2, the limiting current 
corresponding to the reduction plateau could be plotted against the square root of the rotation speed as in the Levich's model [14].

The observation of the electrode surface after the CA experiment by applying -1 V vs SCE at $500 \mathrm{rpm}$ during 140 minutes of electrodeposition highlighted cubic-shaped crystals which has been obtained by SEM (Fig. 3a) and corresponds to calcite form [10, 15]. It has been verified by XRD analysis performed on the deposits. The recorded spectrum displayed in Fig. $3 \mathrm{~b}$ confirmed that the $\mathrm{CaCO}_{3}$ sample constituted mainly by the calcite form.

\subsection{CA modeling of nucleation-growth process of calcium carbonate}

In the present work, the rotating disk electrode (RDE) was used to obtain controlled conditions of convective diffusion of $\mathrm{O}_{2}$ reduction at the bare electrode surface and then at the calcite/ electrode interface. The model assumptions were: i) the steady-state conditions; ii) no convection effects caused by the walls of the cell where the experiment is carried out, nor effects resulting from the finite dimensions of the electrode i.e. no edge effects [16]; iii) the migration has not been taken into account according to the presence of the supporting electrolyte. The mass transport problem related to reaction (1) is described by convectivediffusion equation (4)

$$
D \cdot \nabla^{2} C-V \cdot \nabla C=0
$$

The fluid dynamics problem of a RDE for a constant rotation speed and for a fluid with constant physical properties was solved by Von Karman [17] and Cochran [18] and used by Barcia et al for anodic dissolution of metals under mass transport control [19]. Levich applied these equations to solve the convective-diffusion equations in the case of the rotating disk electrode [14]. The equations of the fluid velocity components near to the rotating disk can be expressed as follow 


$$
\begin{aligned}
& V_{y}=-0.51 \omega^{3 / 2} v^{-1 / 2} y^{2} \\
& V_{r}=0.51 \omega^{3 / 2} v^{-1 / 2} r y
\end{aligned}
$$

where $V_{y}\left(\mathrm{~cm} \cdot \mathrm{s}^{-1}\right)$ and $V_{r}\left(\mathrm{~cm} \cdot \mathrm{s}^{-1}\right)$ are axial velocity component and radial velocity component, respectively, $\omega$ is the rotation speed in $\operatorname{rad}^{-1} \mathrm{~s}^{-1}, v$ is the kinematic viscosity of the electrolyte $\left(\mathrm{cm}^{2} \cdot \mathrm{s}^{-1}\right), y$ and $r$ are axial distance from disk $(\mathrm{cm})$ and radial coordinate $(\mathrm{cm})$, respectively.

The current reflects the change in the concentration gradient at the vicinity of the electrode surface. It can be easily computed by the classical integral equation:

$$
I_{L}=\left.\int n F D \frac{\partial C}{\partial y}\right|_{0} d S
$$

where $C$ is the concentration of electroactive species, $n$ is the number of electrons involved in the electronic transfer reaction, $F$ is Faraday's constant, $S$ is the electrode surface area, $D$ is the diffusion coefficient of electroactive species in the electrolyte.

The numerical values of the all parameters mentioned above for numerical resolution are listed in table 2 for dioxygen.

Numerical resolution of the mass-transfer equations described below was performed by using finite elements. The domain area was divided into subdomains which were delimited by nodes where the unknown (C) were discretizated. The domain has been meshed using Lagrange triangular quadratic elements. Triangular elements were selected to allow local mesh refinement. It is well adapted to the problem of concentration profiles for convergence and ensured that the solution is accurate and independent of the fineness of the mesh. The 
distance of the simulation area, $y_{\infty}$, was taken as 10 -fold higher than the diffusion layer thickness, $\delta_{O 2}$, of the RDE in order to avoid meshing effects.

\subsubsection{Dioxygen reduction on a bare electrode surface}

To simplify the resolution from a $3-D$ to a $2-D$, an axial symmetry was found to decrease computation time as described through the domain area description given in Fig. 4.

The concentration profile in the diffusion layer is governed by the one dimensional steady equation of convective diffusion

$$
D_{O_{2}} \frac{\partial^{2} C_{O_{2}}}{\partial y^{2}}-V_{y} \frac{\partial C_{O_{2}}}{\partial y}=0
$$

The boundary conditions for the case of the bare electrode are

$$
\begin{aligned}
& C_{\mathrm{O}_{2}}(y \rightarrow \infty)=C_{\mathrm{O}_{2}}^{\infty} \text { (bulk solution) } \\
& C_{\mathrm{O}_{2}}(y=0)=0 \quad \text { (limiting current) }(10)
\end{aligned}
$$

The convective-diffusion equation (8) was solved in order to calculate the concentration gradient and then equation (7) was used to calculate the limiting current diffusion at various rotation speeds. Fig. 5 compared the results of the numerical simulation, Levich curve and experimental points for the reduction current on the diffusion plateau at $-1 \mathrm{~V} / \mathrm{SCE}$. It shows a good agreement between the obtained results from numerical simulation at various rotation speeds with the expected theoretical limiting current. Indeed, the theoretical limiting current was described by the well-known Levich equation

$$
\begin{gathered}
I_{L}=4 F D_{O_{2}} C_{O_{2}}^{\infty} \frac{S}{\delta_{O_{2}}} \\
\delta_{O_{2}}=1.61 D_{O_{2}}^{1 / 3} v^{1 / 6} \omega^{-1 / 2}
\end{gathered}
$$

Where $\delta_{\mathrm{O} 2}$ is estimated at $28 \mu \mathrm{m}$ for a rotation speed equals to $500 \mathrm{rpm}$. 
The results displayed in Fig.5 confirm that the dioxygen reduction at the interface electrodesolution is governed by linear diffusion verifying the Levich conditions.

\subsubsection{Dioxygen reduction on a blocked surface}

The dissolved dioxygen reduction was supposed to diffuse through the heterogeneous porous layer (in the $y$-direction) constituted by calcite blocks on carbon steel. In agreement with previous models derived for calcium carbonate electrocrystallization [4], it was assumed that the unit area of the substrate had a finite and constant number of nucleation active sites, $N_{0}\left(\mu \mathrm{m}^{-2}\right)$, and that all sites were assumed to be converted into nuclei.

By considering, the hypothesis that the growth of the nucleus, $S_{n u c l}$, was considered as linear with time, the nucleus surface could be supposed to obey to the following equation

$$
S_{\text {nucl }}(t)=k_{L} \cdot t=d^{2}
$$

where $k_{L}\left(\mu \mathrm{m}^{2} \min ^{-1}\right)$ and $d(\mu \mathrm{m})$ were defined as the lateral growth rate and $\mathrm{CaCO}_{3}$ crystal length, respectively.

The covered surface by the scale deposit without effect of overlapping could be expressed as

$$
\theta(t)=S_{n u c l}(t) \cdot N_{0}
$$

From equation 13 and 14, the lateral growth rate is equal to

$$
k_{L}=\frac{\theta(t)}{N_{0} \cdot t}
$$

The only measurement of the stationary current does not allow the surface coverage determination. For modeling the nucleation-growth process of calcium carbonate, the surface coverage $\theta(\mathrm{t})$ must be accurately known. According previous work in our laboratory [10], the blocked area ratio of the electrode can be determined from the EIS measurement through calculation of the double layer capacitance $C_{\mathrm{d}}$ values. To this goal, EIS spectra in the high frequency domain at various times during the experiment were carried out from a bare 
electrode until a completely blocked surface (see Appendix A). Indeed, the variation of $C_{\mathrm{d}}$ value measured by EIS versus time was directly correlated to the active surface and $C_{\mathrm{d}}$ constitutes a characteristic parameter for the surface coverage. As a consequence, $C_{\mathrm{d} 0}$ is the capacitance value at $t=0$ for a bare electrode and $\left(1-C_{\mathrm{d}} / C_{\mathrm{d} 0}\right)$ ratio represents the fraction of the covered electrode area $(\theta)$ calculated using in situ EIS measurements. This procedure was checked successfully in previous works $[10,21]$. In the present paper, the obtained data are presented in Fig.6 and show the fractional area covered by $\mathrm{CaCO}_{3}$ deposition which was increasing with time and follows the empirical law in equation (16) according to equation (15) where the lateral growth is not linear with time.

$$
\theta(t)=1-\exp \left(-10^{-4} \cdot\left(78.5 \cdot t+4.3 \cdot t^{2}\right)\right)
$$

$\theta$ The geometry of the active site was assuming rectangular with its length, perpendicular to the streamline of the flow (see Fig. 7), and by disregarding the diffusion in the $z$-direction, the problem was reduced in two dimensions $(x$ and $y)$. As a consequence, the complete mass balance equation was simplified as

$$
V_{x} \frac{\partial C_{O_{2}}}{\partial x}+V_{y} \frac{\partial C_{O_{2}}}{\partial y}=D_{O_{2}}\left(\frac{\partial^{2} C_{O_{2}}}{\partial x^{2}}+\frac{\partial^{2} C_{O_{2}}}{\partial y^{2}}\right)
$$

The series expansions of velocity components $V_{x}$, and $V_{y}$ were limited to the first term as described previously in reference [23].

$$
\left\{\begin{array}{l}
V_{x}=\sqrt{V_{r}^{2}+V_{\theta}^{2}}=0.80 \cdot r \omega^{3 / 2} v^{-1 / 2} y \\
V_{y}=-0.51 \cdot \omega^{3 / 2} v^{-1 / 2} y^{2}
\end{array}\right.
$$

For modeling $\mathrm{CA}$ curves during $\mathrm{CaCO}_{3}$ deposition scaling, a 2-D and 3-D growth models were considered. It is assumed that the lateral growth of the crystal is on the surface of the substrate itself and the crystal blocked totally the corresponding surface. This assumption is different to the one of Gabrielli et al [24] who considers that the face of the calcite crystal can 
do a small angle with the substrate. Due to the fact that a residual small current exists even at the long immersion time under consideration, a free active surface must exist and no overlapping is considered in this work. Firstly, lateral growth was considered in the 2-D model, i.e. growth in the parallel direction from the electrode surface (Fig.8a). In this model it was assumed that thickness of crystal on the electrode was neglected (Fig. 8b). The current intensity was normalized with $I_{0}$, the maximum current intensity obtained for each curve. It is also also the Levich current measured on a bare electrode. This latter operation makes easier comparison between different experiments. The modeled curves obtained at a fixed rotation speed $(500 \mathrm{rpm})$ were plotted with time for various values of site density $N_{0}$, and were superimposed on the experimental curve as displayed in Fig. 9. The results highlight the effect of site density on the $\mathrm{O}_{2}$ reduction current intensity. In the first minutes of the experiment, the count of the nuclei indicated no effect on the current intensity. The influence of lateral growth rate of $\mathrm{CaCO}_{3}$ crystals seems to be predominant at the scaling start. The value of $\mathrm{N}_{0}=2 \times 10^{-4}$ $\mu \mathrm{m}^{-2}$ was found in a good agreement with the experimental curve for time shorter than 40 minutes as observed in Fig. 9. At a constant surface coverage, the surface of each nuclei decreases with the number of nuclei $N_{0}$ and as a consequence the current, which is mass transport limited, increases.

Secondly, for time longer than 40 minutes, vertical growth was considered in the $3-D$ model i.e. growth in the vertical direction from the electrode surface (fig. 10a). As indicate in Fig. $10 \mathrm{~b}$, in a first approximation, the vertical growth rate, $k_{\mathrm{V}}$, was assumed to be linearly dependent with the lateral growth rate, $k_{\mathrm{L}}$, and by assuming that cube-like centers were formed (calcite).

$$
\begin{gathered}
k_{V}=\alpha \cdot k_{L} \\
S_{V}=k_{V} \cdot t=h \cdot d
\end{gathered}
$$


From equations 13,19 and $20, \alpha$ is equal to

$$
\alpha=\frac{h}{d}
$$

where $\alpha$ is a constant, $S_{\mathrm{v}}\left(\mu \mathrm{m}^{2}\right)$ and $h(\mu \mathrm{m})$ were the vertical nucleus surface and $\mathrm{CaCO}_{3}$ thickness, respectively. From experimental observations it was noticed that $h$ is inferior to $\delta_{\mathrm{O} 2}$, the diffusion layer thickness of oxygen.

The previous $N_{0}$ found value of $2 \times 10^{-4} \mu \mathrm{m}^{-2}$ was taken as the optimum value of the site density and was inputted in the current intensity calculation with $k_{\mathrm{V}}$ values for $\mathrm{CaCO}_{3}$ growth. The normalized current obtained at various values of $k_{\mathrm{V}}$, calculated from equations (15) and (19), were displayed in Fig. 11a and superimposed with the same experimental curve as seen previously in Fig. 9. As mentioned above, it was observed that the influence of vertical rate growth of the crystals is more important for time larger than 40 minutes because the obtained curves split by far than those obtained in Fig.9. For $\alpha$ values between 0 and 0.5 no correspondence were found with the experimental curve. This indicates that the linearity approximation used in equation 19 was not valid. To solve this problem, calculations were performed point by point taken into account that $\alpha$ varied with time. The procedure was consisted to determine the ratio $k_{\mathrm{V}} / k_{\mathrm{L}}$ at each time on the experimental curve of Fig.9. As seen in Fig.11a at time shorter than 40 minutes the ratio $k_{\mathrm{V}} / k_{\mathrm{L}}$ is close to zero confirming no influence of $k_{\mathrm{V}}$ on the growth rate. However, at time longer than 100 minutes the ratio $k_{\mathrm{V}} / k_{\mathrm{L}}$ is close to 0.5 indicating that $k_{\mathrm{V}}$ could reach by half of the $k_{\mathrm{L}}$ value. To verify $\alpha$ dependence with time, the current intensities were calculated in order to fit the experimental curve all the 10 minutes from start $(t=0)$ to end $(t=140)$ minutes. Data obtained are presented in Fig. $11 \mathrm{~b}$ and show a good agreement between the experimental curve and the fitted curve. In figure 12 
the observed dependence of $\alpha$ was plotted with time and highlights the relationship between $k_{\mathrm{V}} / k_{\mathrm{L}}$. The evolution of $k_{\mathrm{V}} / k_{\mathrm{L}}$ ratio with time varies according to following relation

$$
\ln \alpha=\ln \frac{k_{V}}{k_{L}}=-6.08+0.054 \cdot t
$$

This result shows that 3-D model is adequate for the modeling $\mathrm{CaCO}_{3}$ nucleation-growth process at electrode material. The parameter $\alpha$ was increased with the time up to a value of 0.5. For higher values of time, a plateau was observed. The measurements of the stationary current $I(\mathrm{t})$ and of the surface coverage $\theta(\mathrm{t})$ allowed lateral and vertical growth rate determination.

- For $t \leq t_{\text {critical }}$

$$
\begin{gathered}
k_{L}=\frac{\theta(t)}{2 \times 10^{-4} \cdot t} \\
k_{V}=\exp (-6.08+0.054 \cdot t) \cdot k_{L}
\end{gathered}
$$

- For $t>t_{\text {critical }}$

$$
\begin{gathered}
k_{L}=\frac{1}{2 \times 10^{-4} \cdot t} \\
k_{V}=0.5 \cdot k_{L}
\end{gathered}
$$

In agreement with observations and results described above, the variations of $d$ and $h$ dimensions of $\mathrm{CaCO}_{3}$ crystal with time have been calculated using equations (13-14) and (21), respectively. Fig. 13 shows that $\mathrm{CaCO}_{3}$ crystals mainly grow laterally for time lower than 40 minutes. That is observed through the linear variation of $d$ whereas $h$ is close to zero. Indeed, the vertical growth has no influence on the beginning of the nucleation-growth process. For time comprises between 40 and 100 minutes, $d$ increases again until reaching a plateau value of $50 \mu \mathrm{m}$. At the same time, $h$ increases until a maximum value of $25 \mu \mathrm{m}$. This latter value is close to $\delta_{\mathrm{O} 2}(28 \mu \mathrm{m})$, which had been estimated with equation (12), and reinforces the assumption that $h$ cannot exceed the diffusion layer width $\left(h<\delta_{\mathrm{O} 2}\right)$. For time 
higher than 100 minutes, $d$ and $h$ are remain stables, that is again in agreement with the fact that the vertical and lateral growths tend towards zero. Theses obtained plateau values for $h=$ $25 \mu \mathrm{m}, d=50 \mu \mathrm{m}$ and for the site density number $N_{0}=2 \times 10^{-4} \mu \mathrm{m}^{2}$ allow to derive the corresponding $\theta$ value, which is found to be equal to 50 percent of the electrode surface using equations (13) and (14). A half-surface coverage could be explained by the overlapping of crystals on electrode surface as observed in Fig. 3 which has no taking into consideration in the model. However, these results confirm that the model works well and it is valid for investigation of nucleation-growth process..

\section{Conclusions}

In this paper, it was shown that the equation governing convective diffusion in complex electrochemical systems can be solved by finite element method. The data analysis of the chronoamperometric curves were used for investigating nucleation and growth kinetics of $\mathrm{CaCO}_{3}$ on electrode. CA has permitted obtention of information on the screening effect of the insulating scale deposit on electrode surface and in particular, it has allowed discrimination between $2-D$ and $3-D$ blocking by modeling the mass transfer phenomena at mineral water solution/ carbon steel interface. The model elaborated in this work predicts within a good accuracy the relative contributions of 3- $D$ growth to the nucleation-growth process of calcium carbonate at disk electrode. It was found that the effect of vertical growth of the crystals is negligible at the beginning of the scaling phenomenon.

\section{Acknowledgments}

We thank Stephan Borensztajn and Françoise Pillier at "Laboratoire Interfaces et Systèmes Electrochimiques - Université Pierre \& Marie Curie, UPMC Paris 6" for technical assistance on SEM micrographs acquisition, Cyril Bazin for X-Ray diffraction experiment. This research was supported by the French research organism "Institut de Recherche pour le développement" (IRD). 


\section{References}

[1] H. Roques, Fondements théoriques du traitement chimique des eaux. Tec \& Doc, Lavoisier, Paris, 1990.

[2] H. Teghidet, M. C. Bernard, S. Borensztajn, L. Chaal, S. Joiret, B. Saidani, Calcite epitaxy on Au and Ag (1 1 1), J. Cryst. Growth 331 (2011) 72.

[3] J. Rinat, E. Korin, L. Soifer, A. Bettelheim, Electrocrystallization of calcium carbonate on carbon-based electrodes, J. Electroanal. Chem. 575 (2005) 195.

[4] L. Beaunier, C. Gabrielli, G. Poindessous, G. Maurin, R. Rosset, Investigation of electrochemical calcareous scaling Nuclei counting and morphology, J. Electroanal. Chem. $501(2001) 41$.

[5] C. Gabrielli, M. Keddam, H. Perrot, A Khalil, R. Rosset, M. Zidoune, Characterization of the efficiency of antiscale treatments of water -Part I: Chemical processes, J. Appl. Electrochem.26 (1996) 1125.

[6] C. Gabrielli, G. Maurin, G. Poindessous, R. Rosset, Nucleation and growth of calcium carbonate by an electrochemical scaling process, J. Cryst. Growth 200 (1999) 236.

[7] O. Devos, C. Gabrielli, B. Tribollet, Nucleation-growth processes of scale crystallization under electrochemical reaction investigated by in situ microscopy, Electrochem. Solid-State Lett. 4 (10) (2001) C73-C76.

[8] O. Devos, C. Gabrielli, M. Tlili and B. Tribollet, Nucleation-growth process of scale electrodeposition: influence of the supersaturation, J. Electrochem. Soc. 150 (2003) C494C501.

[9] F. Hui, J. Lédion, Evaluation methods for the scaling power of water, J. Eur. of Water Qual. 33, Fasc. 1 (2002). 
[10] O. Devos, C. Gabrielli, B. Tribollet, Simultaneous EIS and in situ microscope observation on a partially blocked electrode application to scale electrodeposition, Electrochim. Acta 51 (2006) 1413.

[11] H. S. Ras, S. Ghizellaoui, Determination of anti-scale effect of hard water by test of electrodeposition, Procedia Engineering 33 (2012) 357.

[12] C. Gabrielli, G. Maurin, H. Perrot, G. Poindessous, R. Rosset, Investigation of electrochemical calcareous scaling Potentiostatic current - and mass - time transients, J. Electroanal. Chem. 538-539 (2002) 133.

[13] O. Devos, C. Gabrielli, B. Tribollet, Nucleation-growth process of scale electrodeposition-Influence of the mass transport, Electrochim. Acta 52 (2006) 285.

[14] V. G. Levich, Physiochemical hydrodynamics, Englewood Cliffs, Prentice-Hall, Englewood Cliffs, New Jersey, 1962.

[15] Y. BenAmor, L. Bousselmi, M.C. Bernard, B. Tribollet, Nucleation-growth process of calcium carbonate electrodeposition in artificial water-Influence of the sulfate ions, J. Cryst. Growth 320 (2011) 69.

[16] C. M. A. Brett, A. M. O. Brett, Electrochemistry. Principles, Methods, and Applications, Oxford University Press, New York, 1993.

[17] V. Karman, Uber Laminare und Turbulente Reibung, Z. Angew. Math. Mech. 1 (1921) 232.

[18] W. G. Cochran, The Flow due to a Rotating Disc, Proc. Cambridge Phil. Soc 30 (1934) 365.

[19] E. Barcia, O.R. Mattos, N. Pébère, B. Tribollet, Anodic dissolution of metals under mass transport control, Electrochim. Acta 41 (1996) 1385. 
[20] C. Deslouis, I. Frateur, G. Maurin, B. Tribollet, Interfacial pH measurement during the reduction of dissolved oxygen in a submerged impinging jet cell, J.Appl. Electrochem 27 (1997) 482.

[21] Ch. Barchiche, C. Deslouis, D. Festy, O. Gil, Ph. Refait, S. Touzain, B. Tribollet, Characterization of calcareous deposits in artificial seawater by impedance techniques 3Deposit of $\mathrm{CaCO}_{3}$ in the presence of $\mathrm{Mg}(\mathrm{II})$, Electrochim. Acta 48 (2003) 1645.

[22] A. Caprani. C. Deslouis, S. Robin and B. Tribollet, Transient mass transfer at partially blocked electrodes: a way to characterize topography, J. Electroanal. Chem. 238 (1987) 67. [23] C. Deslouis, B. Tribollet, Non stationary mass transfer in the flow due to a disk rotating in an Ostwald Fluid. Application to the measurement of the molecular diffusion coefficient in a polymer solution, Electrochim. Acta 23 (1978) 935.

[24] C. Gabrielli, M. Keddam, A. Khalil, R. Rosset, M. Zidoune, Study of calcium carbonate scales by electrochemical impedance spectroscopy, Electrochim. Acta 42 (1997) 1207. 


\section{Tables Caption}

Table 1: Chemical composition and characteristics of the mineral water used in this study.

Table 2: Physical parameters used for numerical simulations for dioxygen [20].

\section{Figure captions}

Fig. 1: Current-potential curves for dioxygen reduction in mineral water on steel electrode. Scan rate: $1 \mathrm{mV} . \mathrm{s}^{-1}$.

Fig.2: Limiting current of oxygen reduction as function of $\omega^{1 / 2}$ for a carbon steel electrode in mineral water.

Fig. 3: a. SEM micrographs of $\mathrm{CaCO}_{3}$ formed in the mineral water after $140 \mathrm{~min}$ of immersion. $\omega=500 \mathrm{rpm}, E=-1 \mathrm{~V} / \mathrm{SCE}$. b. X-Ray diffraction pattern of the crystals $\mathrm{CaCO}_{3}$.

Fig. 4: FEM boundary conditions at rotating disk electrode.

Fig. 5: Limiting current as function of $\omega^{1 / 2}$ for a carbon steel electrode in mineral water, $E=-$ 1V vs SCE. The straight line corresponds to Levich equation:

$$
I_{\text {Levich }}=0.62 \cdot n \cdot F \cdot D_{O_{2}}^{2 / 3} \cdot v^{-1 / 6} \cdot \omega^{1 / 2} \cdot C_{O_{2}}^{\infty} \cdot S
$$

Fig. 6: The covered surface by the $\mathrm{CaCO}_{3}$ deposit vs. time obtained through double layer capacitance calculation by EIS measurement.

Fig. 7: Geometry of the problem used for the numerical integration adapted from reference $[22]$.

Fig. 8. Scheme of the considered $2 \mathrm{D}$ crystal growth of $\mathrm{CaCO}_{3}$ on a substrate, $\mathrm{d}: \mathrm{CaCO}_{3}$ crystal length, $l$ : distance between $\mathrm{CaCO}_{3}$ crystals. b. FEM boundary conditions at rotating disk electrode. 2- $\mathrm{D}$ model with lateral growth of $\mathrm{CaCO}_{3}$. 
Fig. 9: Current time-transients plotted with respect to time for various values of the site density $N_{0}, \omega=500 \mathrm{rpm} . \mathrm{I}_{0}=\mathrm{I}_{\text {Levich }}$ has been used for normalization.

Fig. 10: a. Scheme of the considered 3-D crystal growth of $\mathrm{CaCO}_{3}$ on a substrate, $\mathrm{d}$ : $\mathrm{CaCO}_{3}$ crystal length, $l$ : distance between $\mathrm{CaCO}_{3}$ crystals and $h: \mathrm{CaCO}_{3}$ thickness. b. FEM boundary conditions at rotating disk electrode. 3- $\mathrm{D}$ model with vertical growth of $\mathrm{CaCO}_{3}$.

Fig. 11: Current time-transients plotted with time for various values of $k_{\mathrm{V}}, \omega=500 \mathrm{rpm}$. $\mathrm{I}_{0}=$ $\mathrm{I}_{\text {Levich }}$ has been used for normalization.

Fig. 12: Calculated values of $\alpha$ with time. (1): $\ln \alpha=-6.08+0.054 \cdot t$,

(2): $\ln \alpha=\ln (0.5)=-0.69$

Fig. 13. Calculated values of $h$ and $d$ with time. 


\section{List of table}

Table1:

\begin{tabular}{|lllllllllll|}
\hline Species & $\mathrm{Ca}^{2+}$ & $\mathrm{HCO}_{3}{ }^{-}$ & $\mathrm{Mg}^{2+}$ & $\mathrm{Na}^{+}$ & $\mathrm{K}^{+}$ & $\mathrm{Cl}^{-}$ & $\mathrm{NO}_{3}{ }^{-}$ & $\mathrm{F}^{-}$ & $\mathrm{SO}_{4}{ }^{2-}$ & $\mathrm{pH}$ \\
\hline $\mathbf{m g ~ L}^{-1}$ & 112 & 430 & 28 & 6.6 & 1.8 & 8 & $<1$ & 0.6 & 61 & 7.3 \\
\hline
\end{tabular}


Table 2:

\begin{tabular}{|c|c|}
\hline physical parameters & Values \\
\hline$C_{\mathrm{O} 2}{ }^{\infty}$ & $2.2 \times 10^{-4} \mathrm{~mol} . \mathrm{L}^{-1}$ \\
\hline$D_{O 2}$ & $2 \times 10^{-5} \mathrm{~cm}^{2} . \mathrm{s}^{-1}$ \\
\hline$F$ & $96485 \mathrm{C} \cdot \mathrm{mol}^{-1}$ \\
\hline$v$ & $0.01 \mathrm{~cm}^{2} . \mathrm{s}^{-1}$ \\
\hline$n$ & 4 \\
\hline
\end{tabular}


List of figures

Fig. 1:

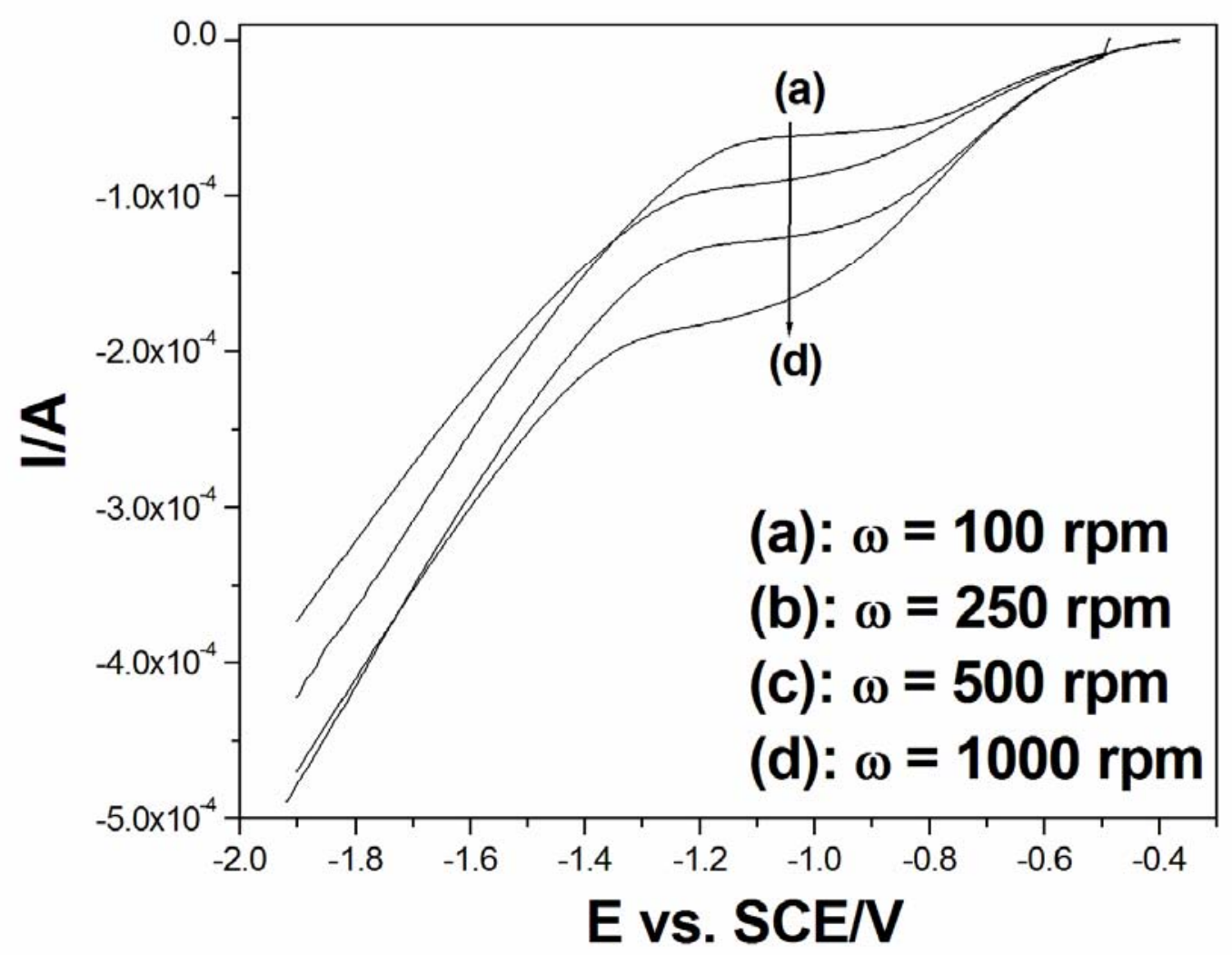


Fig. 2:

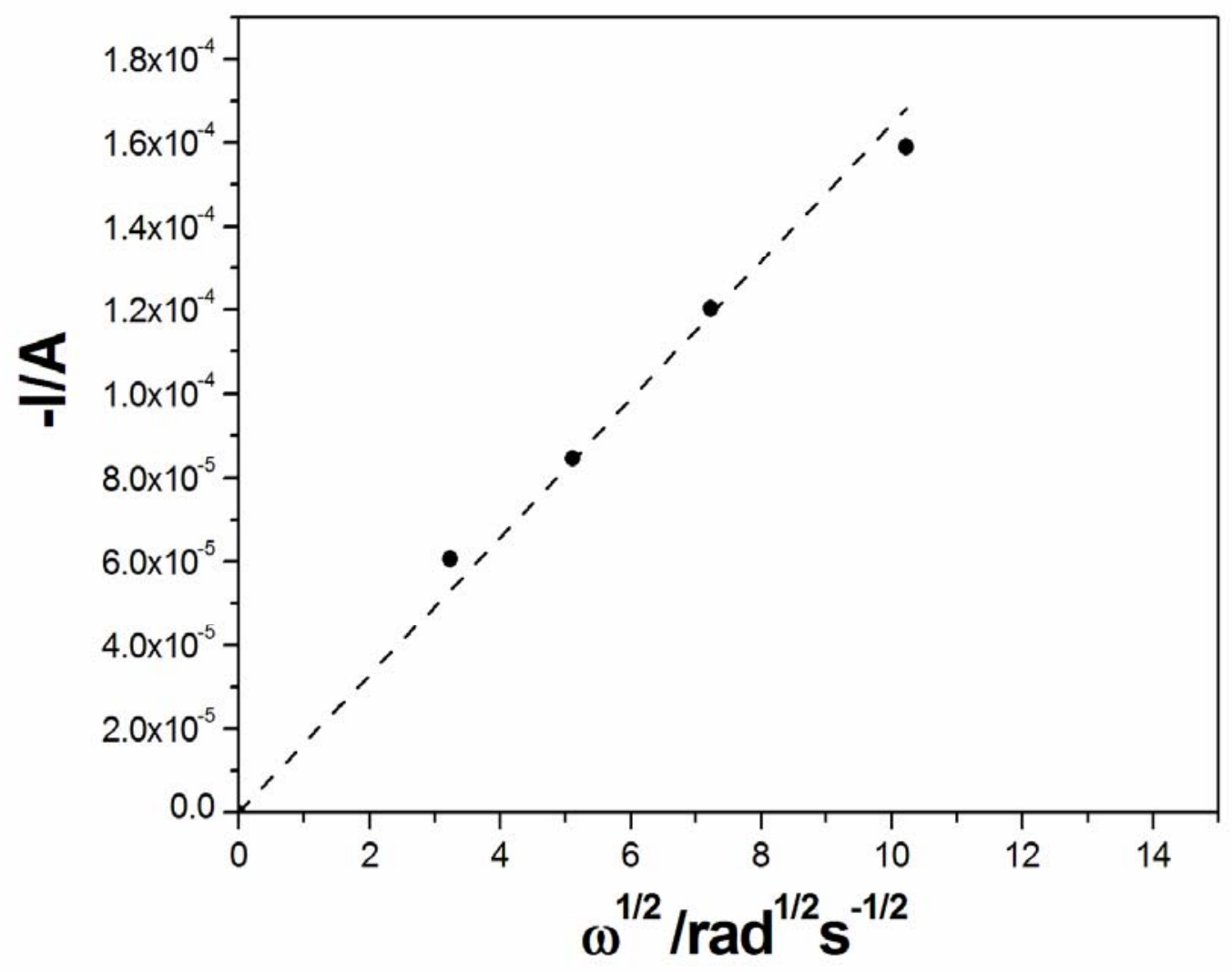


Fig. 3:
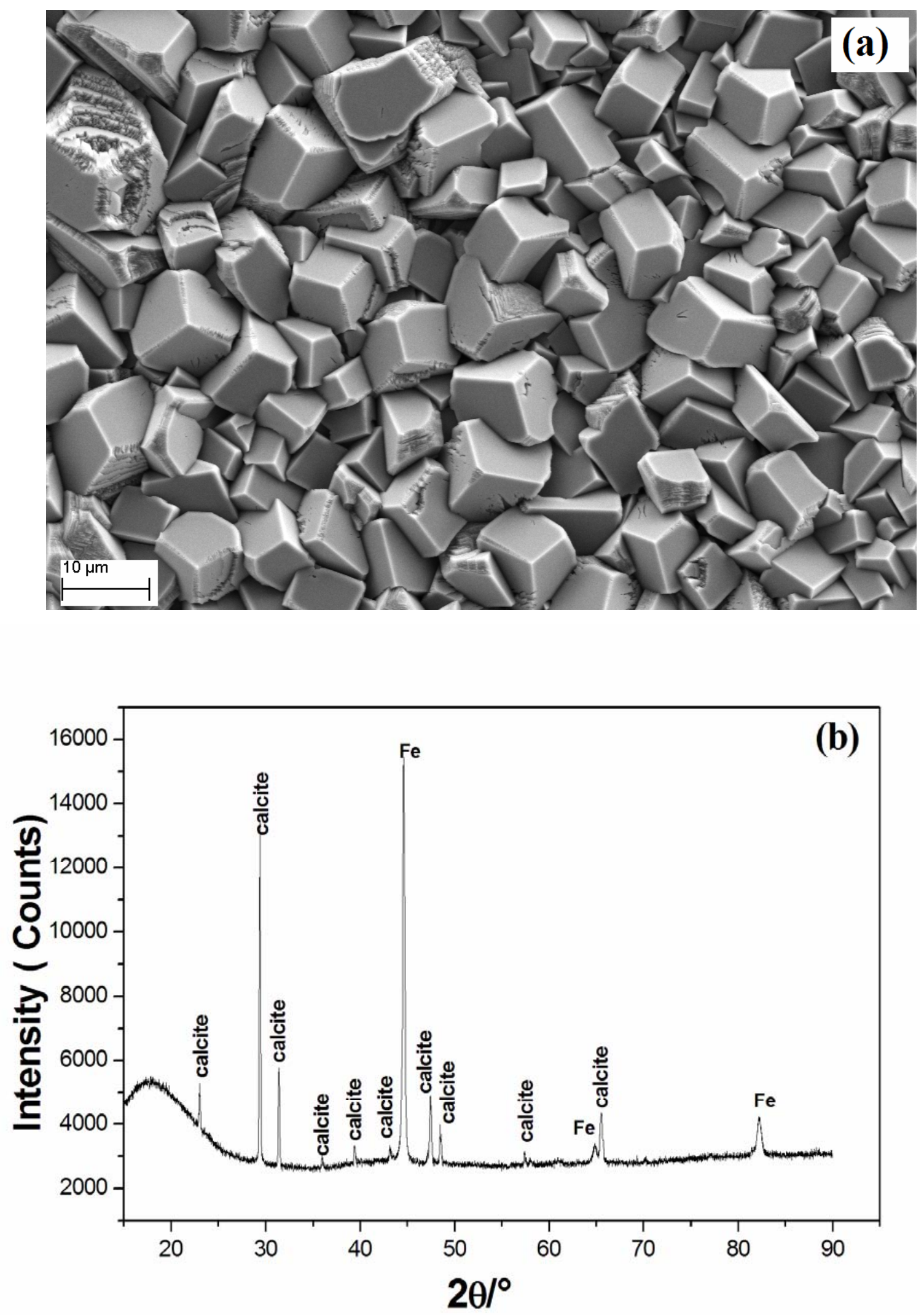
Fig. 4:

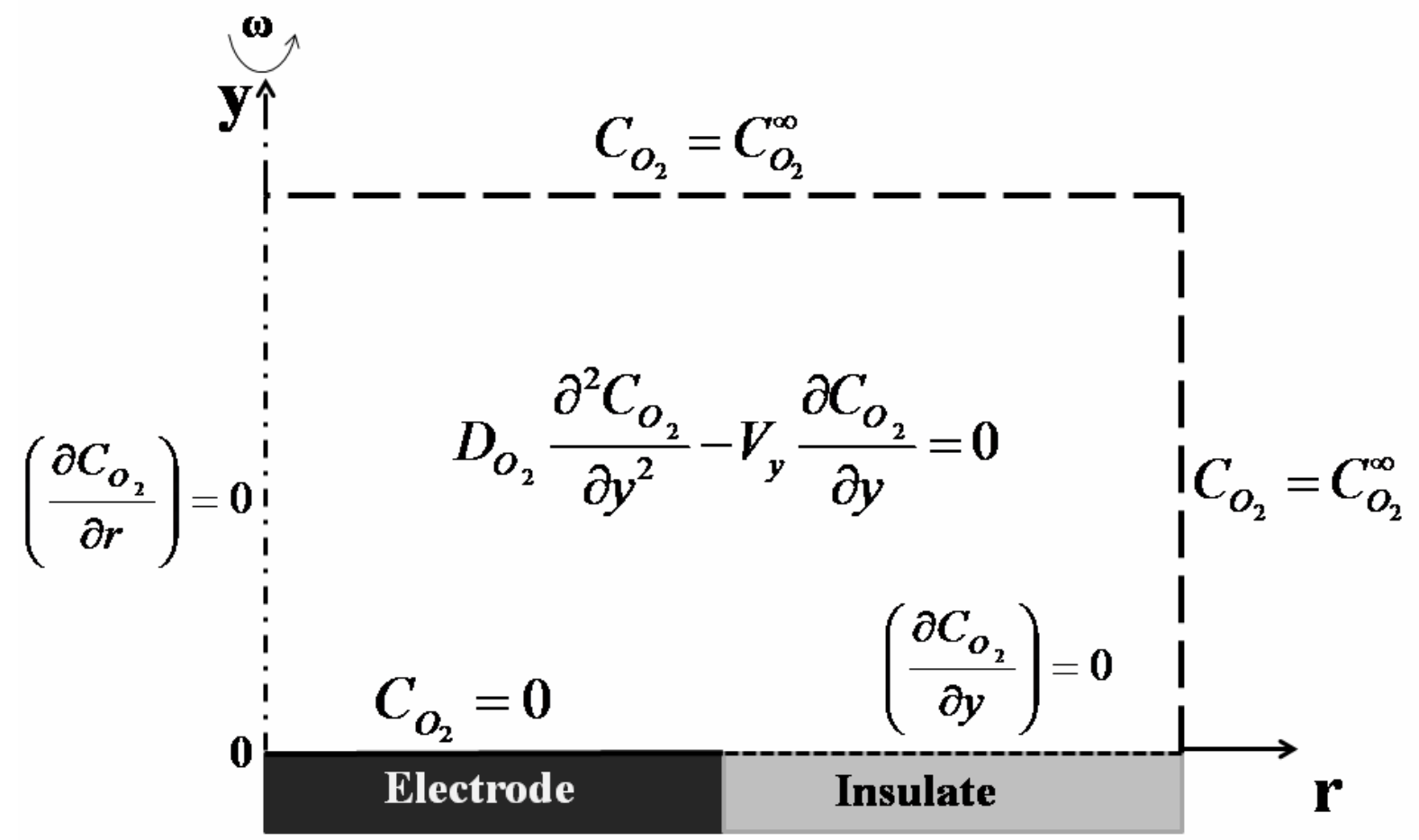


Fig. 5:

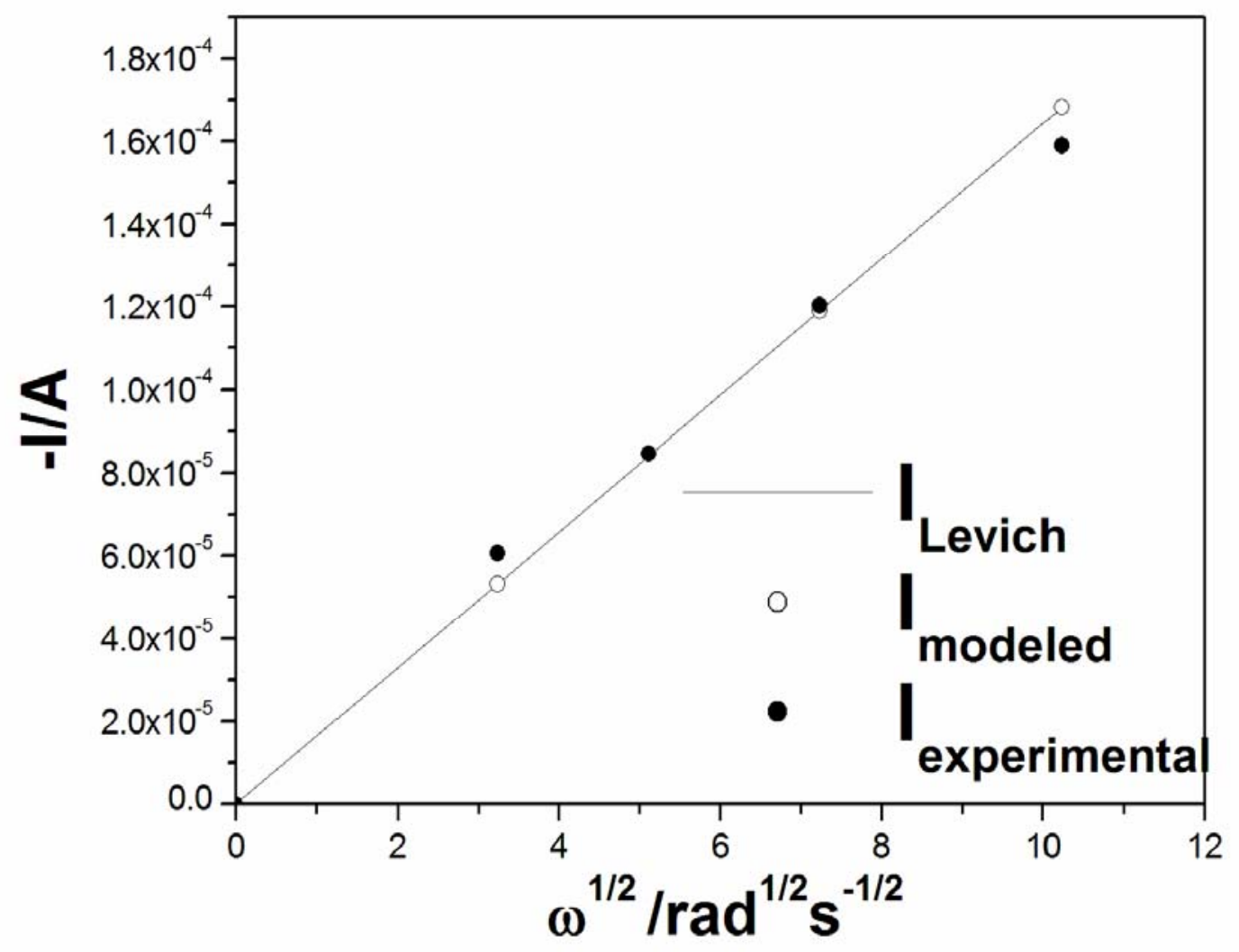


Fig. 6:

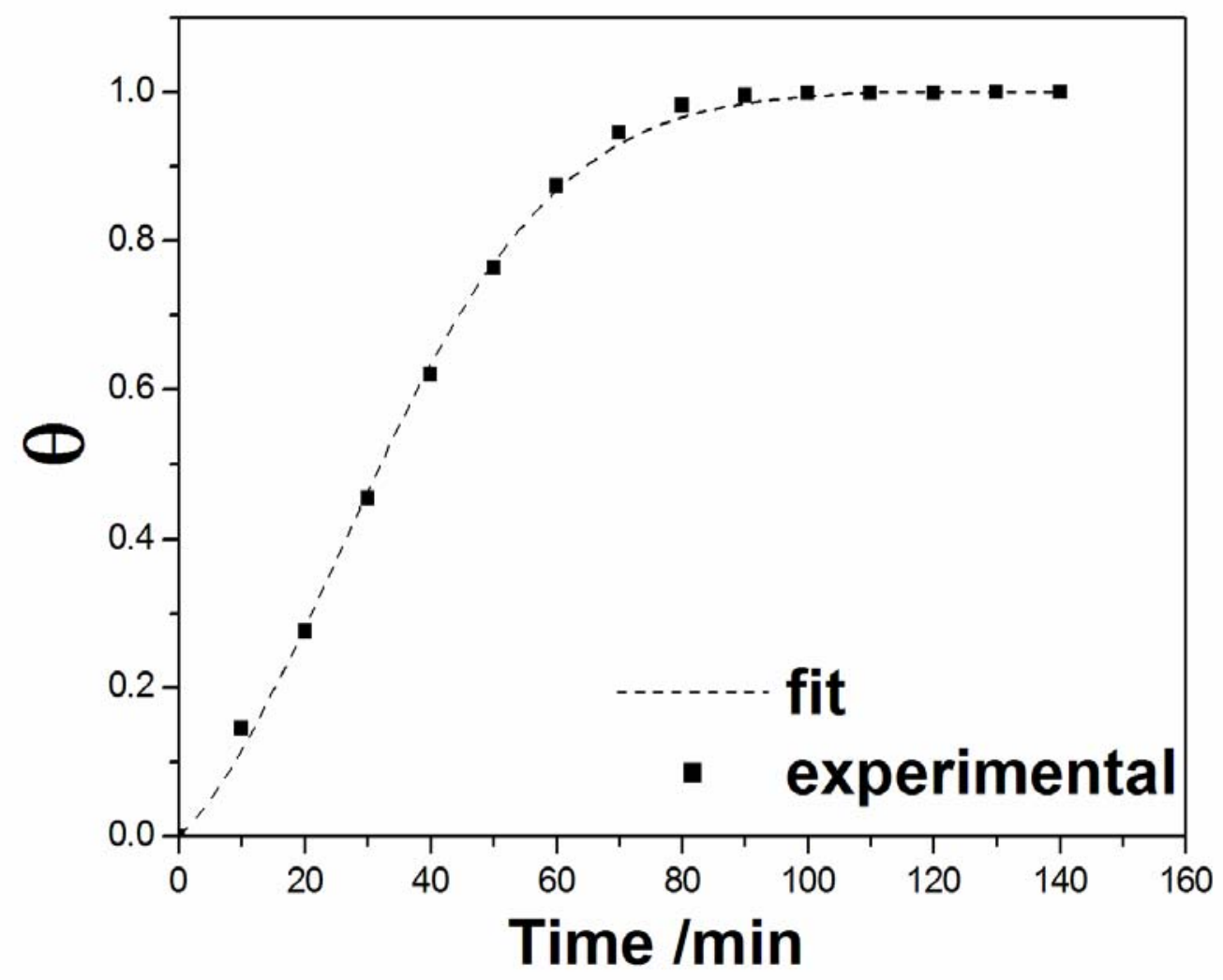


Fig. 7:

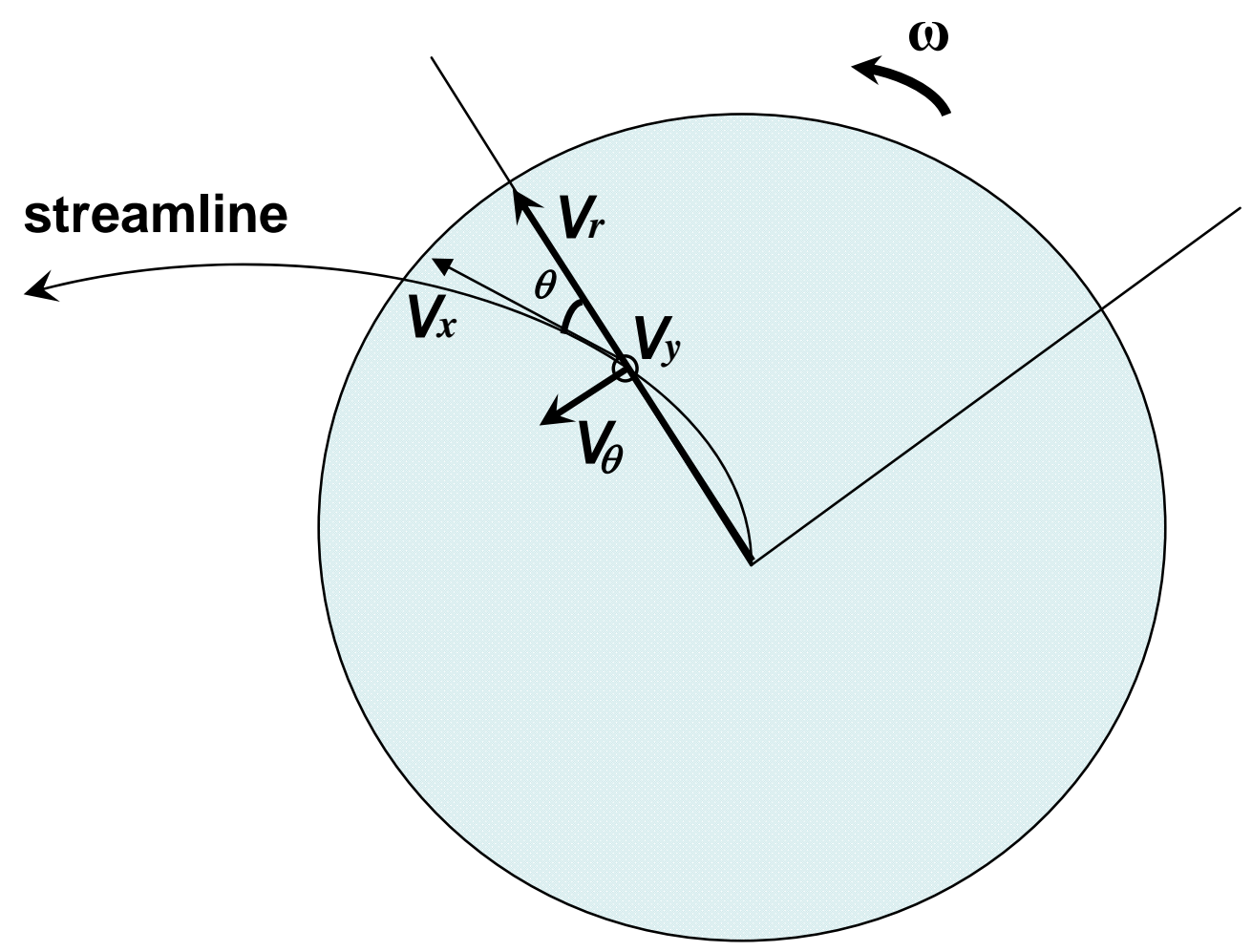


Fig. 8:
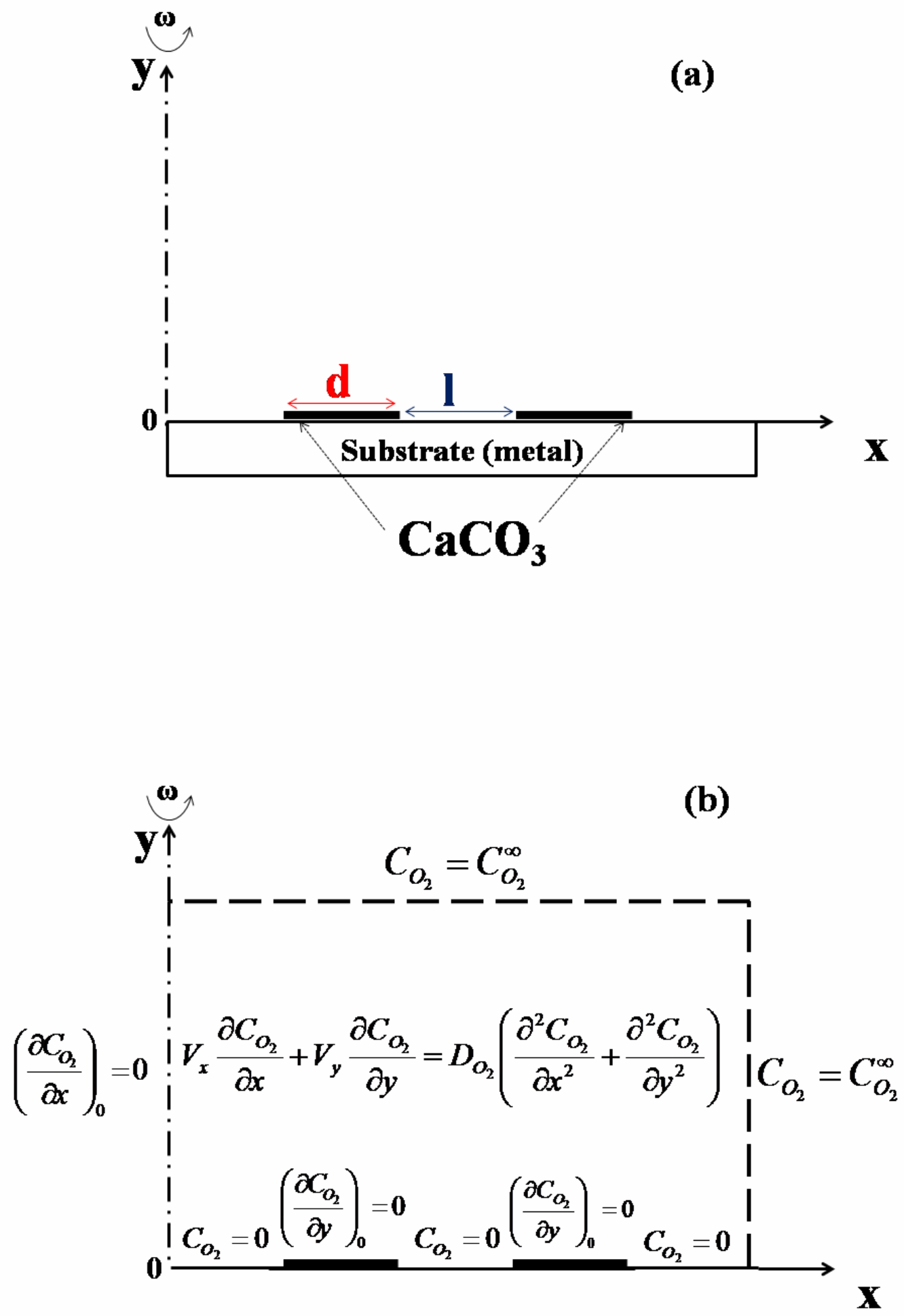

Fig. 9: 


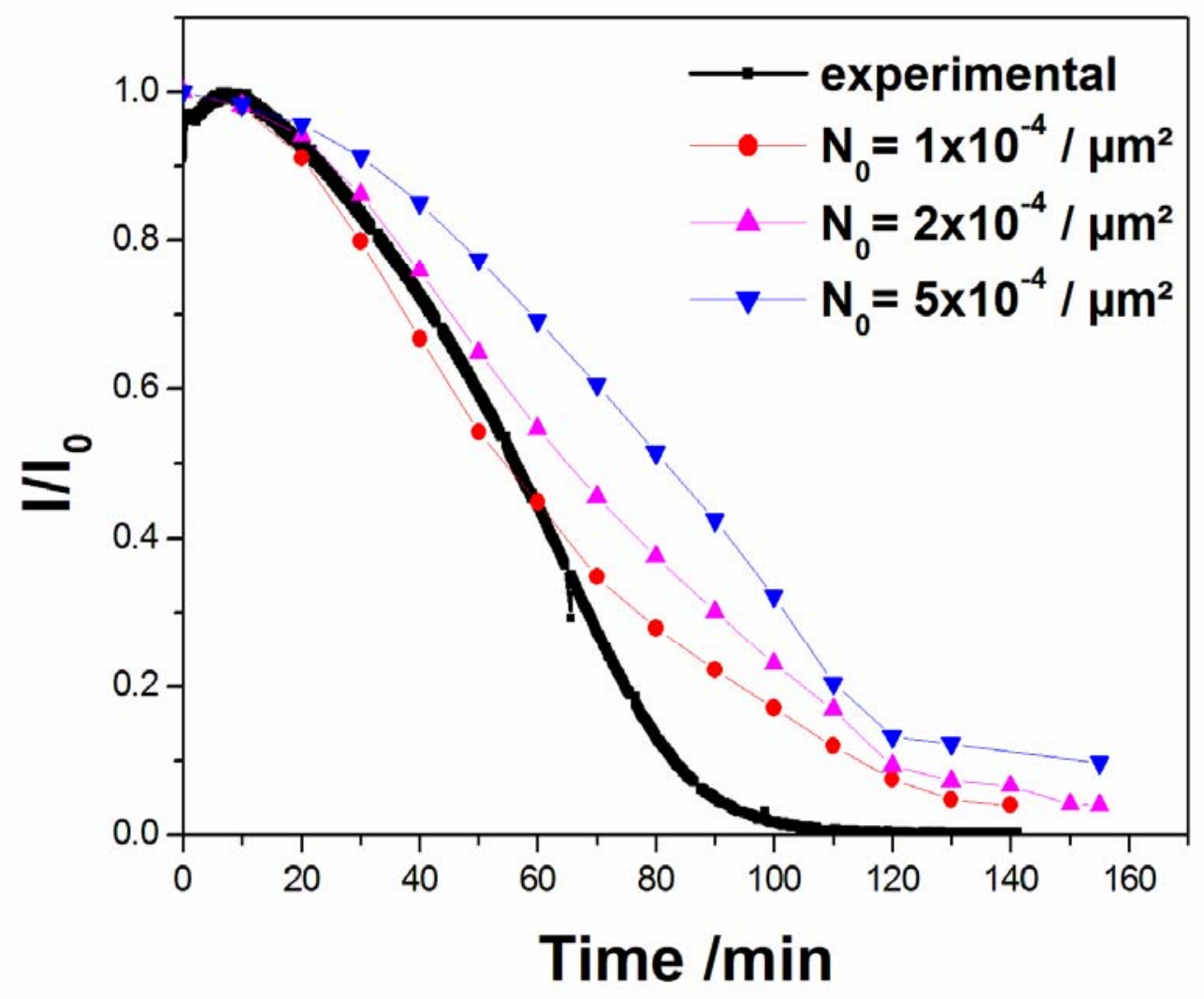


Fig. 10:
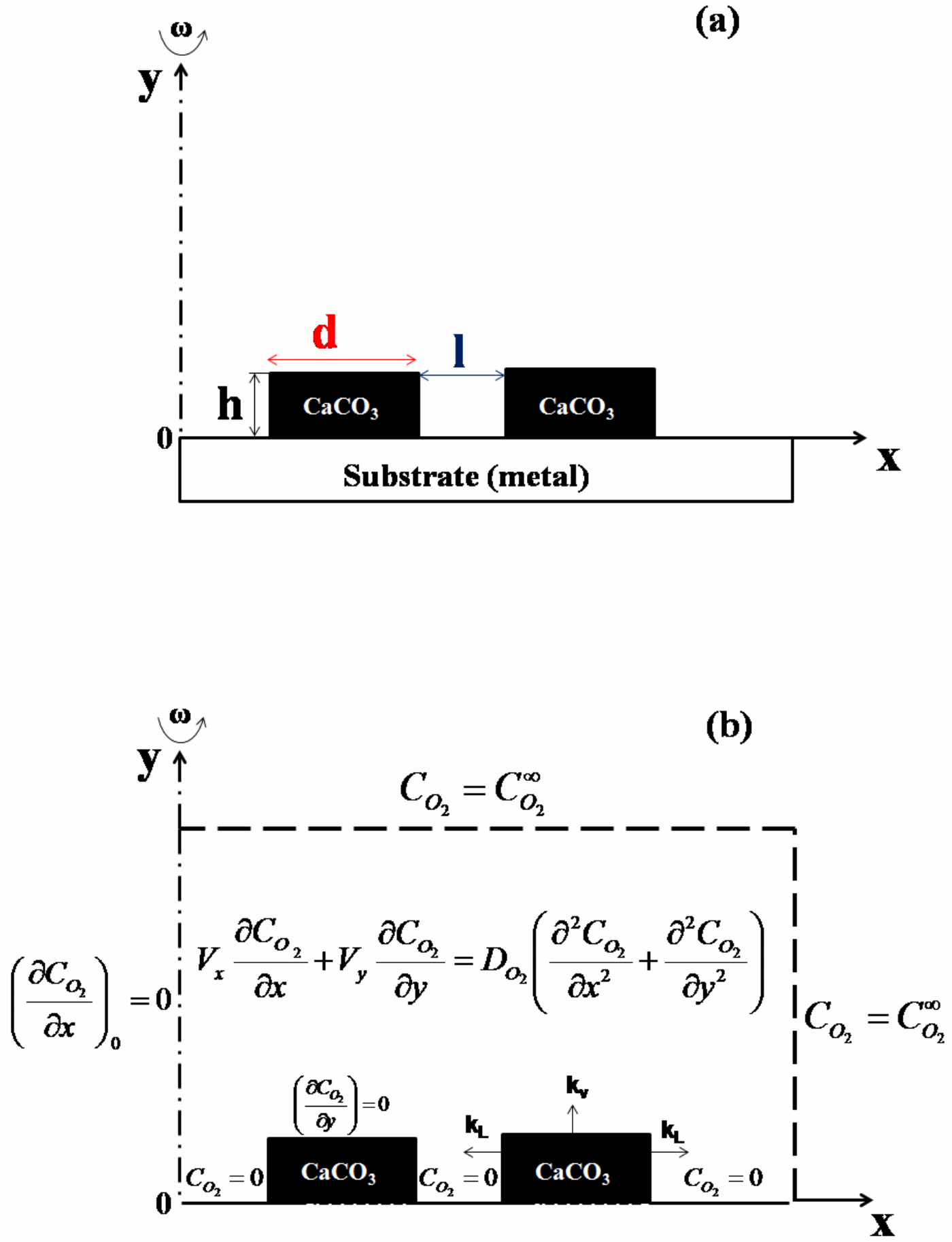
Fig.

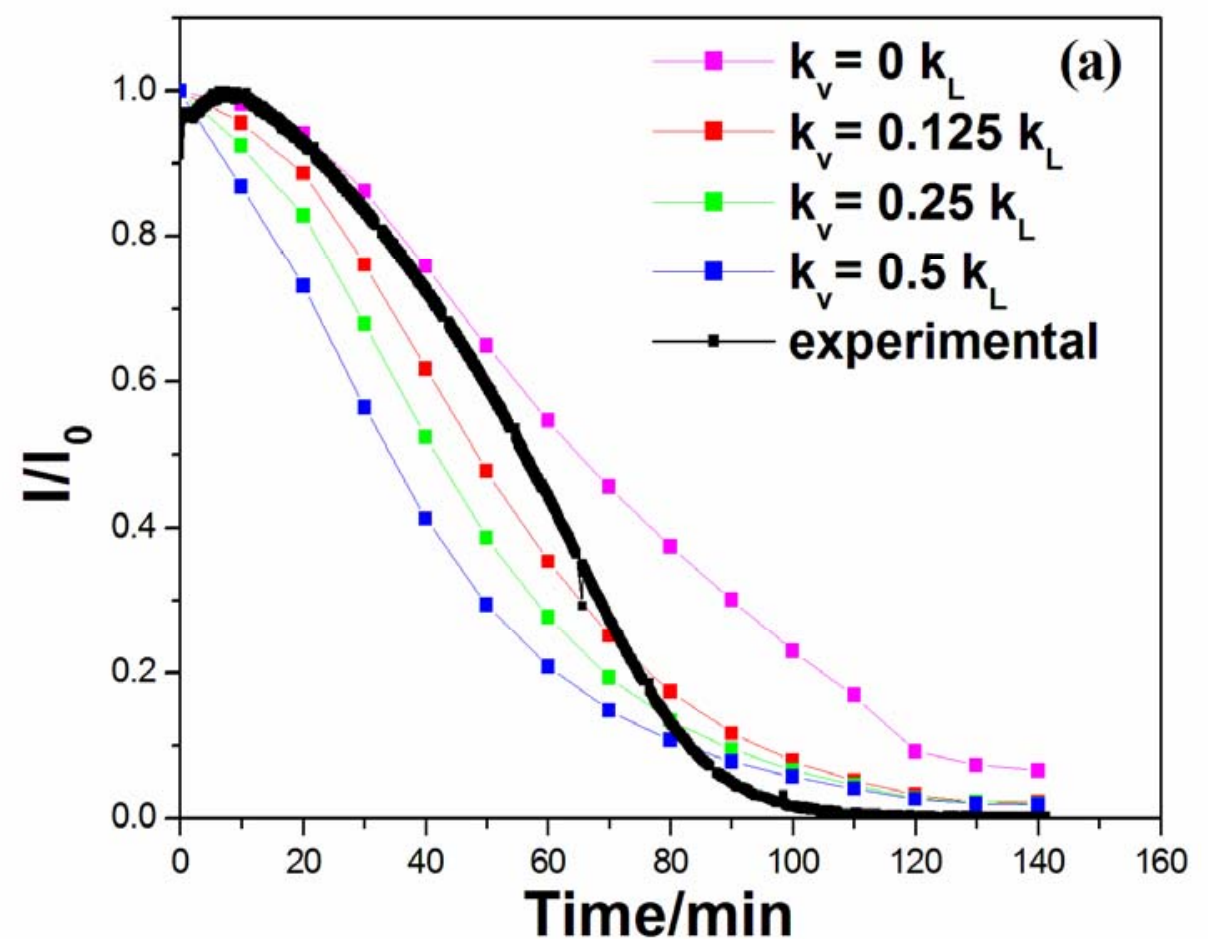

11

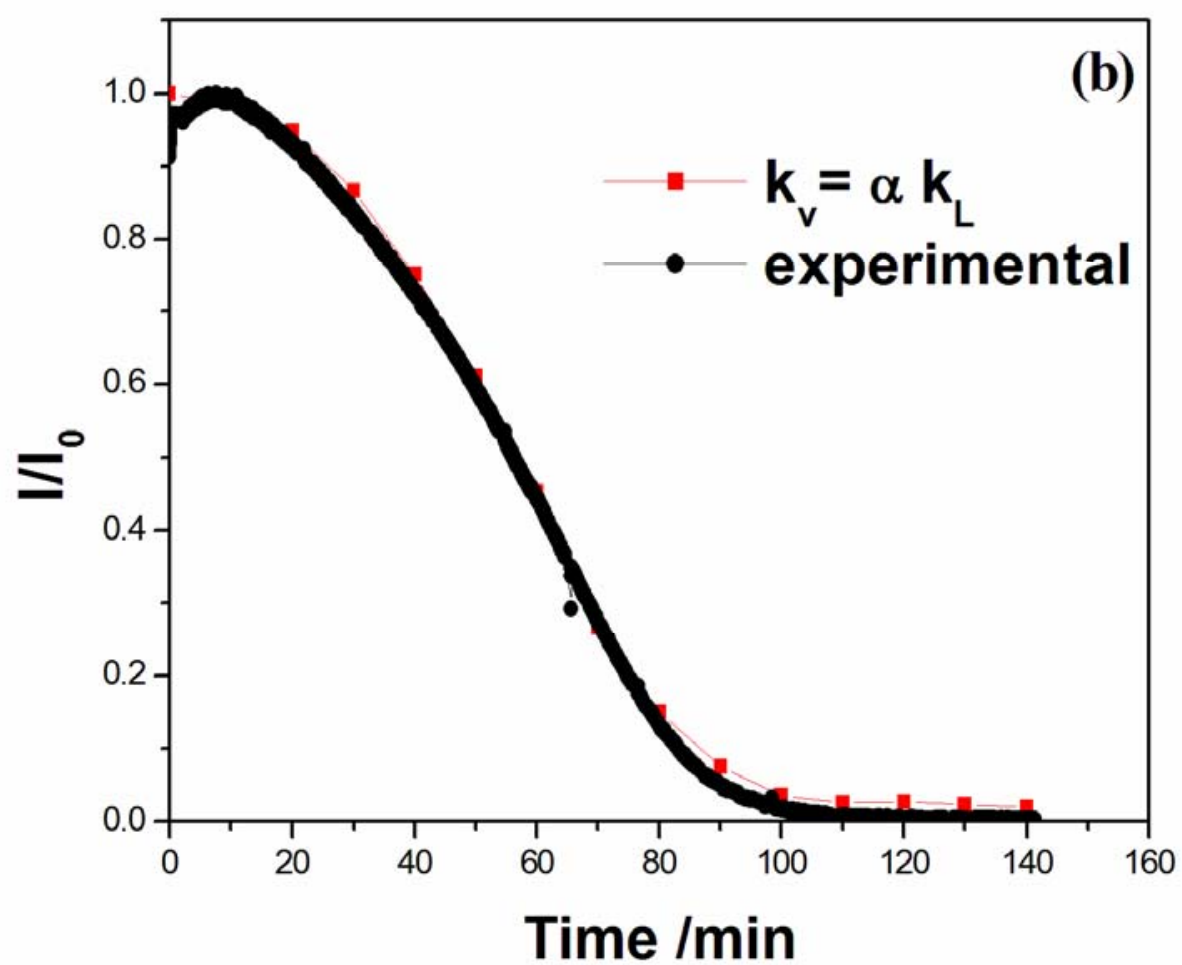


Fig. 12:

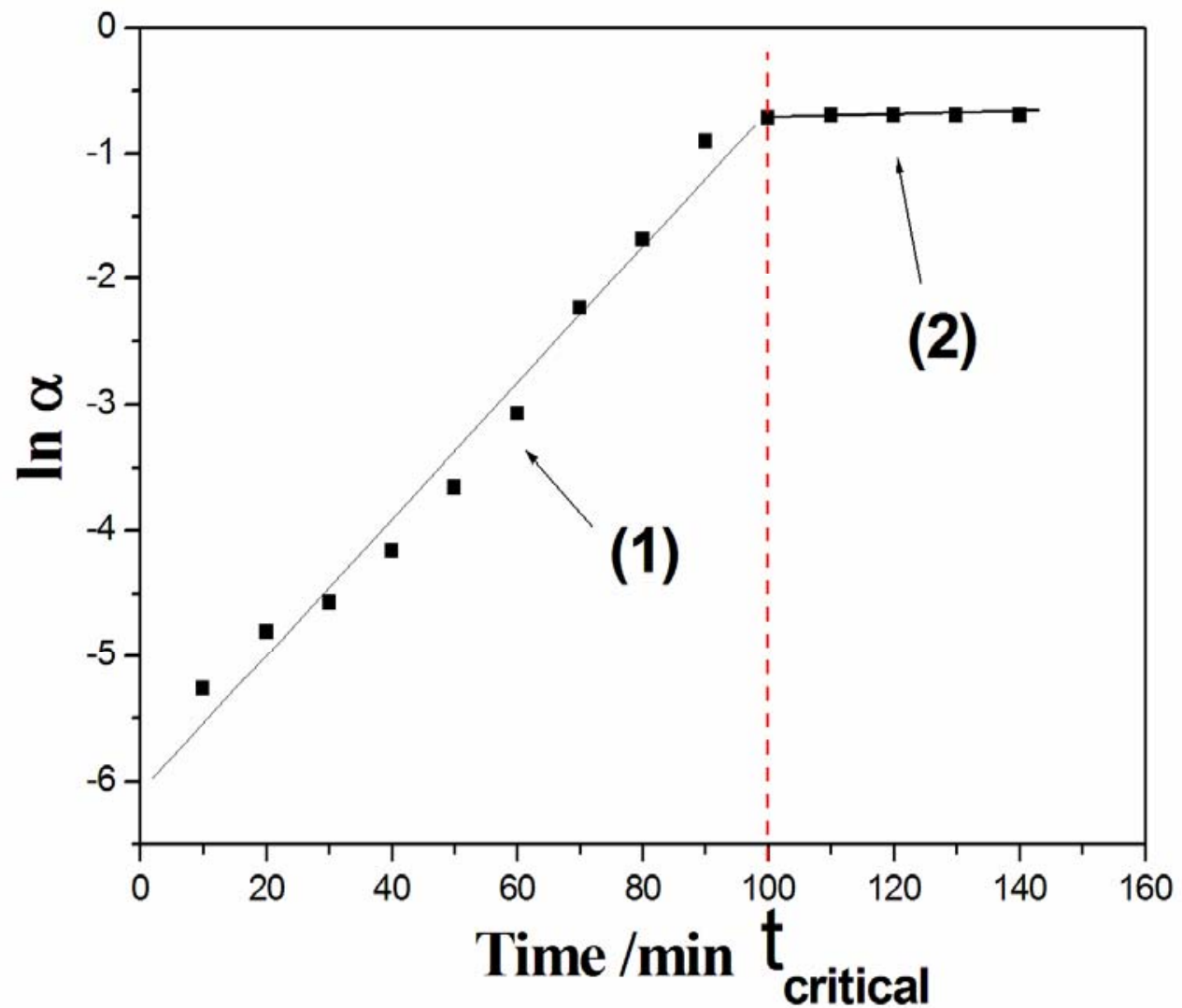


Fig. 13

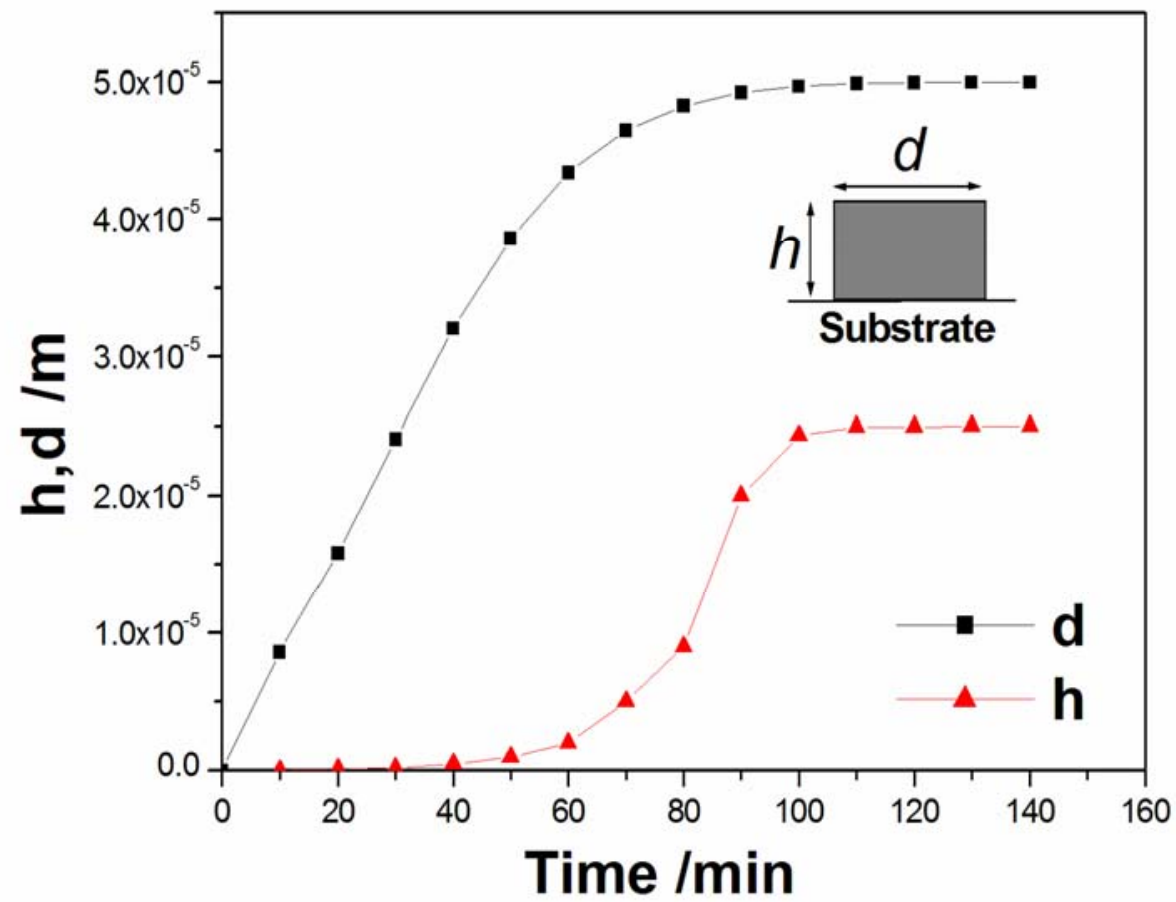

